\title{
Peripheral Decoration of Dibenzofuran with Donors and Acceptors as a New Design Platform of Thermally Activated Delayed Fluorescence Emitters
}

\author{
Hee-Jun Park ${ }^{1+}$, Ha Lim Lee ${ }^{++}$, Ho Jung Lee ${ }^{1+}$, Kyung Hyung Lee', Jun Yeob Lee ${ }^{1^{*}}$, \\ Wan Pyo Hong ${ }^{2 *}$
}

${ }^{1}$ School of Chemical Engineering, Sungkyunkwan University

2066, Seobu-ro, Jangan-gu, Suwon, Gyeonggi, 16419, Republic of Korea

${ }^{2}$ LG Chem, Ltd, LG Science Park, 30, Magokjungang 10-ro, Gangseo-gu, Seoul, 07796, Republic of Korea

\section{General information}

Materials. All reactions were carried out under nitrogen atmosphere unless otherwise noted. Standard Schlenk techniques were employed to manipulate air sensitive solutions while workup procedures were done in air. All solvents utilized in this work were obtained from Fisher Scientific (HPLC grade) unless otherwise noted. All deuterated solvents were purchased from Aldrich. Pentafluorophenylboronic acid and 2bromoanisole were purchased from TCI. Chromatographic purification (Silica Gel 60, 230-400 mesh, Merck) of all compounds was performed on the bench top.

Instruments. ${ }^{1} \mathrm{H}$ NMR, ${ }^{13} \mathrm{C}$ NMR spectra were recorded on an AVMACE III HD (Bruker, $500 \mathrm{MHz}$ ). Chemical shifts for $1 \mathrm{H}$ NMR spectra are relative to a residual proton in the deuterated solvents $\left(\mathrm{CDCl}_{3}, \delta=7.26 \mathrm{ppm}\right)$. All coupling constants are reported in hertz. Electronic absorption spectra were recorded on a JASCO spectrophotometer. Photoluminescence emission spectra were recorded a fluorescence spectrophotometer (PerkinElmer, LS-55) with and without 2 microsecond delay. Cyclic 
voltammetry was performed by purging the acetonitrile (spectroscopic grade) solution by dry nitrogen gas for $10 \mathrm{~min}$. The supporting electrolyte was $0.1 \mathrm{M}$ tetrabutylammonium perchlorate $\left(\mathrm{TBAClO}_{4}\right)$. Glassy carbon and $\mathrm{Ag} / \mathrm{AgCl}(0.01 \mathrm{M}$ $\mathrm{NaCl}$ ) were used as a working and a reference electrode, respectively. The scan rate was maintained at $100 \mathrm{mV} / \mathrm{s}$. The PL quantum yield and transient decay data were recorded on a Quantaurus-QY system (Hamamatsu, C11347-11) and Quantaurus-Tau system (Hamamatsu, C11367-31).

Device Fabrication. The substrates were washed with chloroform, isopropyl alcohol and deionized water for 30 minutes. Material deposition was proceeded under $5.0 \times 10^{-7}$ torr. The deposited device structure was summarized below.

ITO (50 nm)/PEDOT:PSS (60 nm)/TAPC $(20 \mathrm{~nm}) / \mathrm{mCP}(10 \mathrm{~nm}) /$ Emissive layer $(25$ $\mathrm{nm}) / \operatorname{TSPO} 1(5 \mathrm{~nm}) / \mathrm{TPBi}(20 \mathrm{~nm}) / \mathrm{LiF}(1.5 \mathrm{~nm}) / \operatorname{Al}(200 \mathrm{~nm})$

PEDOT:PSS is Poly(3,4-ethylenedioxythiophene)-poly(styrenesulfonate) and used as hole injection layer material. The full name of TAPC is $4,4^{\prime}$-Cyclohexylidenebis $[N, N$ bis(4-methylphenyl)benzenamine], which is used as hole transport layer. 1,3-di(9Hcarbazol-9-yl)benzene (mCP) was used as a role of blocking layer with hole characters. TSPO1 is Diphenyl(4-(triphenylsilyl)phenyl)phosphine oxide and used as electron type exciton blocking layer. As an electron transport layer material, 1,3,5-Tris(1-phenyl-1Hbenzo[d]imidazol-2-yl)benzene (TPBi) was used. In emissive layer, (Oxybis(2,1phenylene))bis(diphenylphosphine oxide) (DPEPO) was used as host material. And the dopants were doped into DPEPO with $10 \sim 40 \mathrm{wt} \%$, respectively.

The solution process device structure was summarized below.

ITO (50 nm)/PEDOT:PSS (60 nm)/PVK (0.3wt\%)/Emissive Layer/TSPO1 (30 nm)/LiF $(1 \mathrm{~nm}) / \mathrm{Al}(200 \mathrm{~nm})$ 
PVK is poly(vinyl carbazole). The PVK solution was prepared in $0.3 \mathrm{wt} \%$ chlorobenzene for $10 \mathrm{~nm}$. The solution was spin-coated at $2000 \mathrm{rpm}$ for 30 seconds and the coated film was annealed at $150{ }^{\circ} \mathrm{C}$ for $40 \mathrm{~min}$. The emitting layer solution was a mixed solution of $1.0 \mathrm{wt} \%$ toluene solution of diphenyldi(4-(9-carbazolyl)phenyl)silane $(\mathrm{SiCz})$ and $0.5 \mathrm{wt} \%$ chlorobenzene solution of $\mathrm{DBFtCzCN}$, and it was spin-coated at a spin speed of $2000 \mathrm{rpm}$ for 30 seconds, followed by annealing at $80^{\circ} \mathrm{C}$ for $20 \mathrm{~min}$. All solution process was conducted in the nitrogen filled glove box.

Hole-only and electron device was fabricated as below structure, respectively.

HOD: ITO $\quad(50 \quad \mathrm{~nm}) /$ PEDOT:PSS $\quad(60 \quad \mathrm{~nm}) /$ TAPC $\quad(20 \quad \mathrm{~nm}) / \mathrm{mCP} \quad(10 \mathrm{~nm}) /$ DPEPO:Emitter (25 nm: $20 \mathrm{wt} \%) /$ TAPC (10 nm)/Al (200 nm)

EOD: ITO (50 nm)/TSPO1 (10 nm)/DPEPO:Emitter $(25 \mathrm{~nm}: 20 \mathrm{wt} \%) / T S P O 1(5$ $\mathrm{nm}) / \mathrm{LiF}(1.5 \mathrm{~nm}) / \mathrm{Al}(200 \mathrm{~nm})$

Electrical and optical analyses were performed using a Keithley 2400 source measurement unit and a CS2000 spectroradiometer. 
(a)

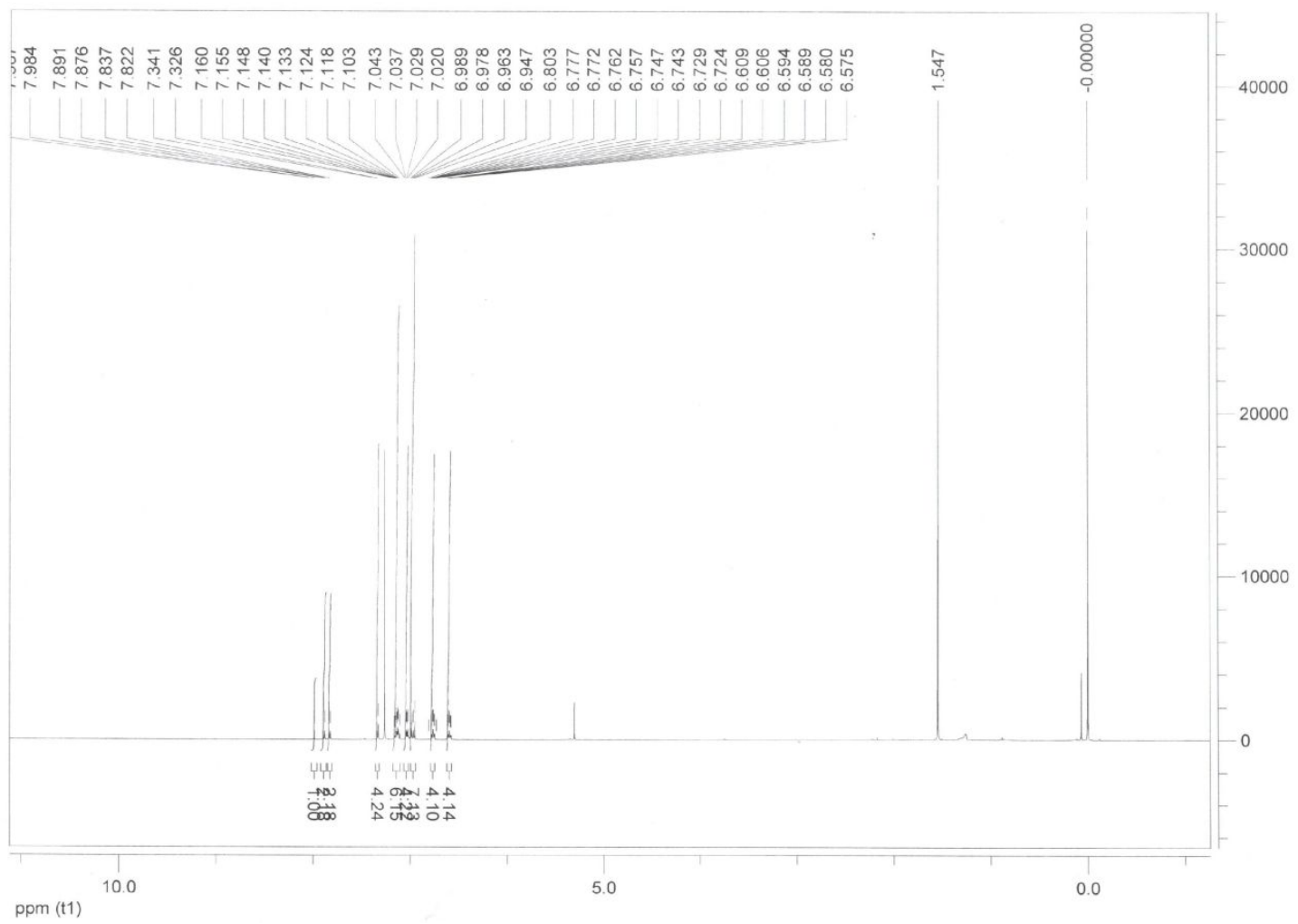

(b)

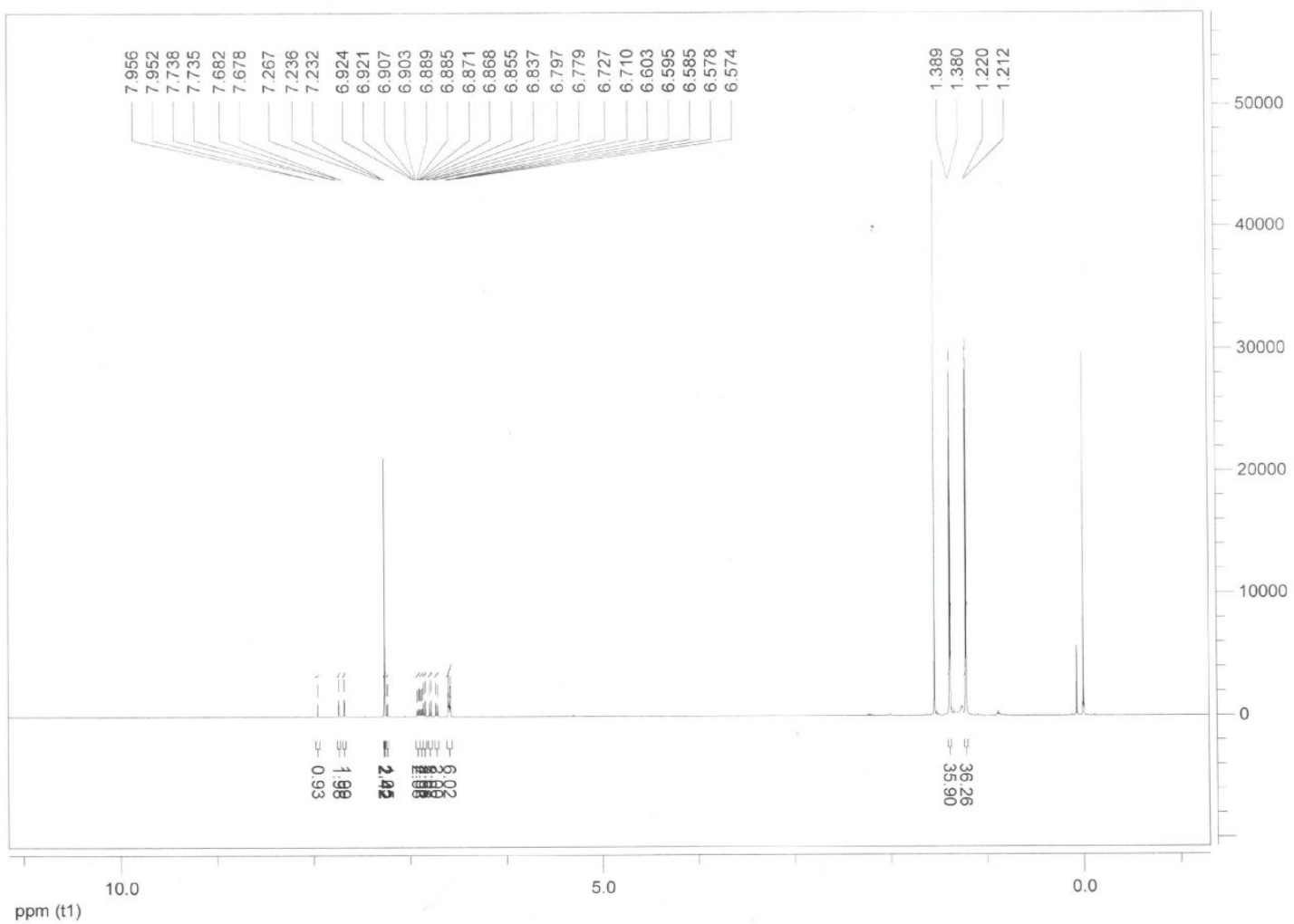

Figure S1. ${ }^{1} \mathrm{H}$ NMR spectrum of (a) $\mathrm{DBFCzCN}$ and (b) DBFtCzCN 
(a)

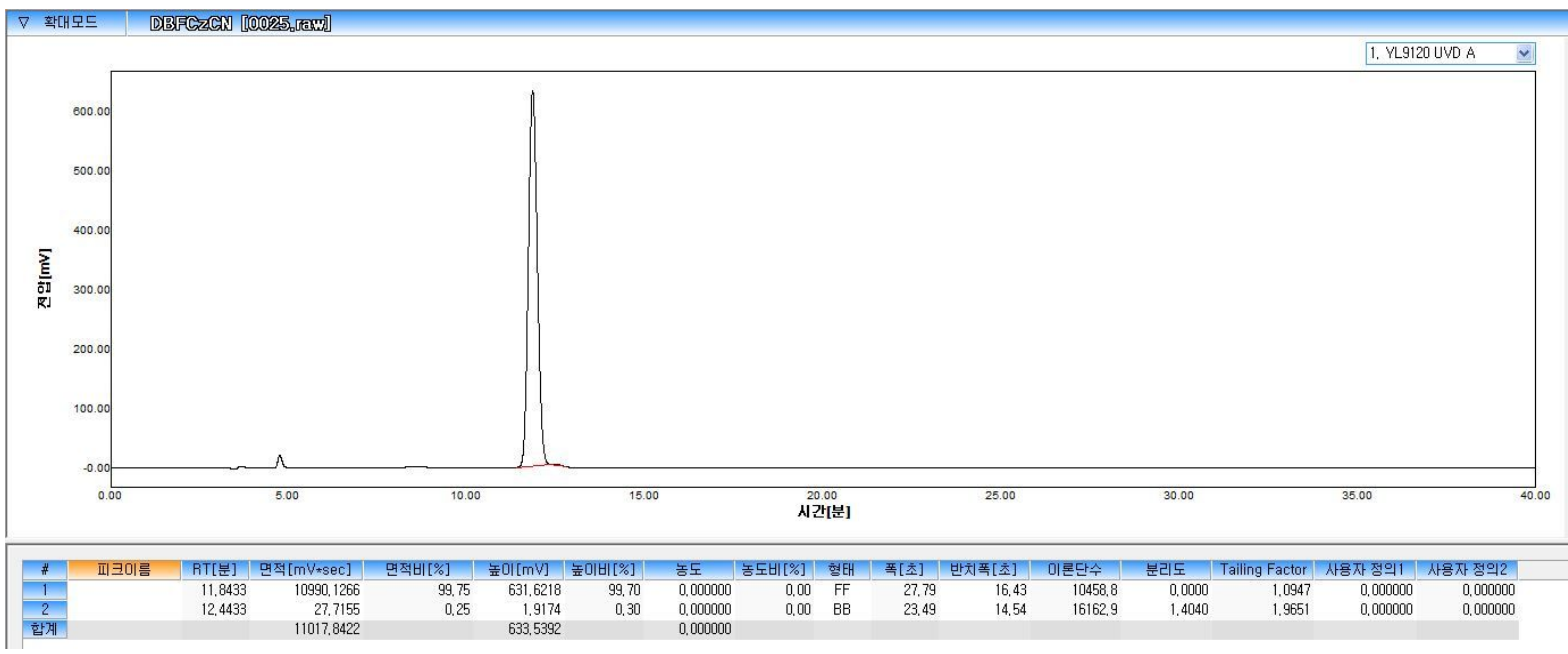

(b)

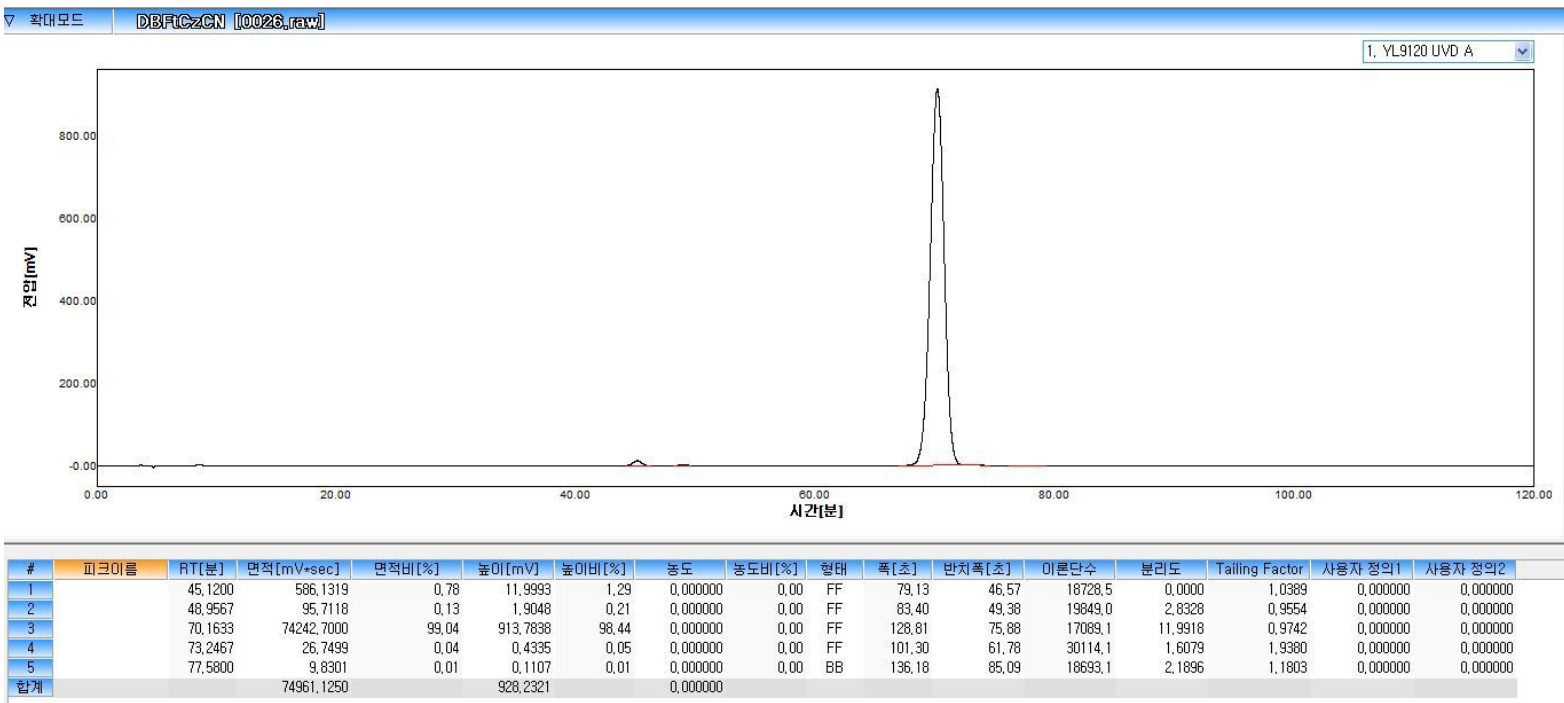

Figure S2. HPLC measurement result of (a) DBFCzCN and (b) $\mathrm{DBFtCzCN}$ 


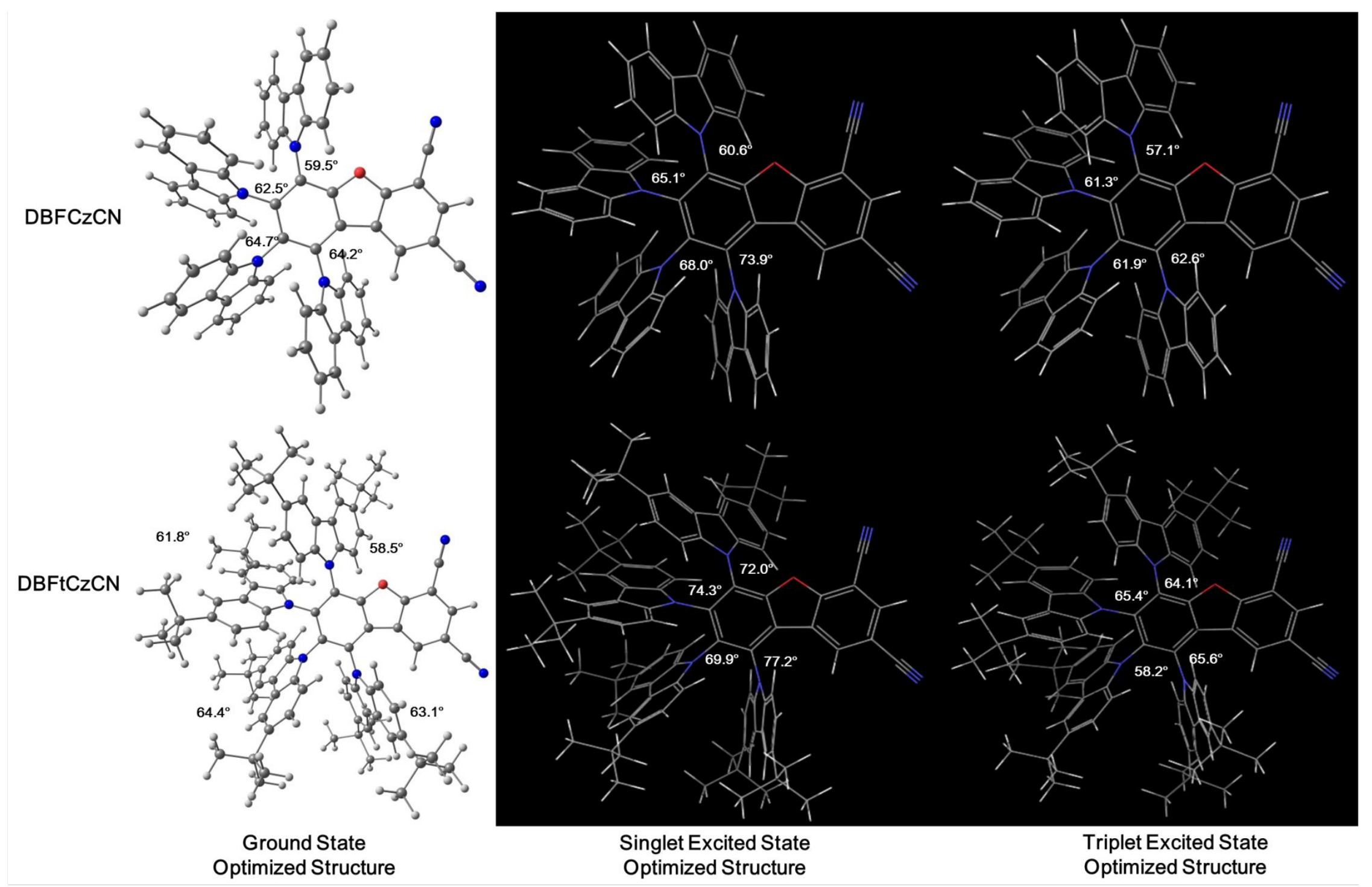

Figure S3. Optimized structure of $\mathrm{DBFCzCN}$ and $\mathrm{DBFtCzCN}$ in ground state, singlet excited state, and triplet excited state. 


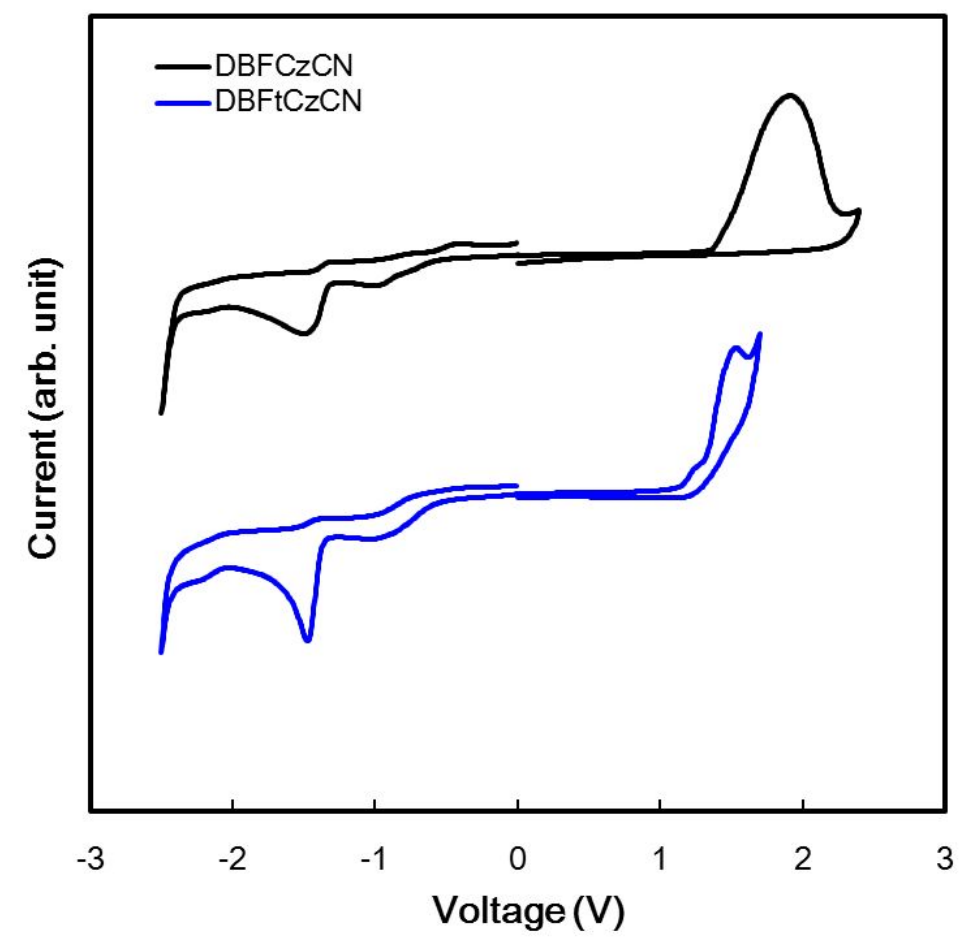

Figure S4. Cyclic voltammetry scan data of $\mathrm{DBFCzCN}$ and $\mathrm{DBFtCzCN}$. 
(a)

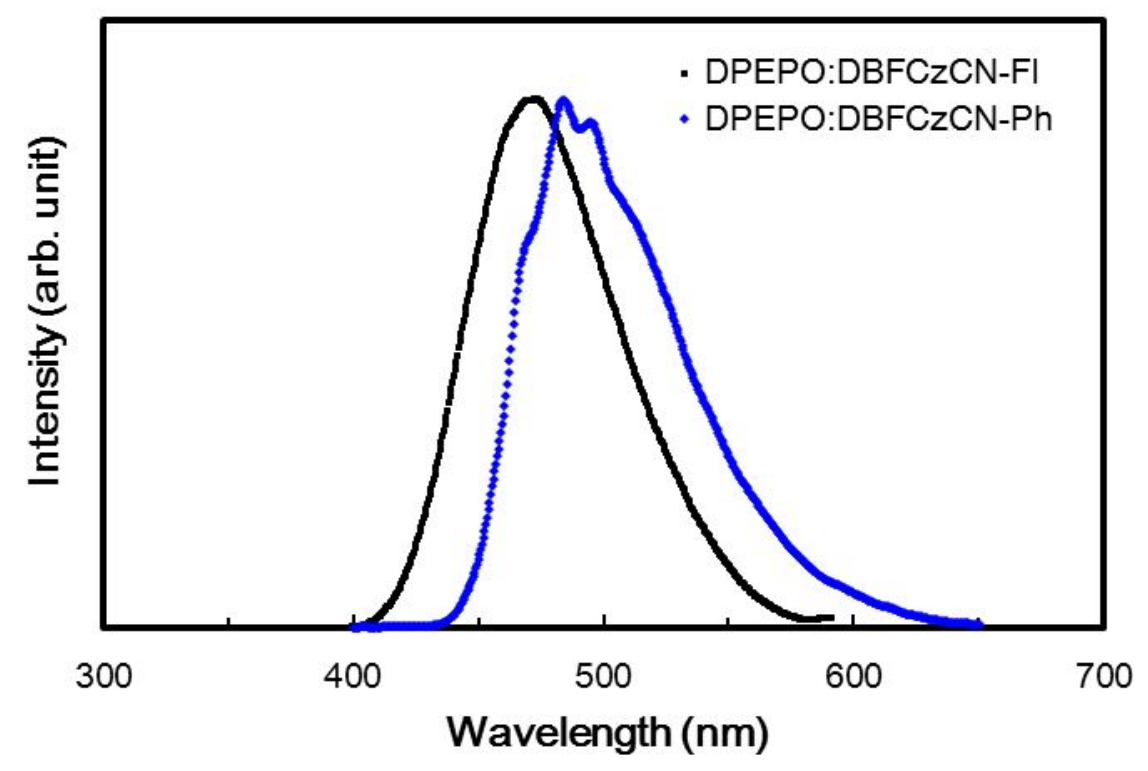

(b)

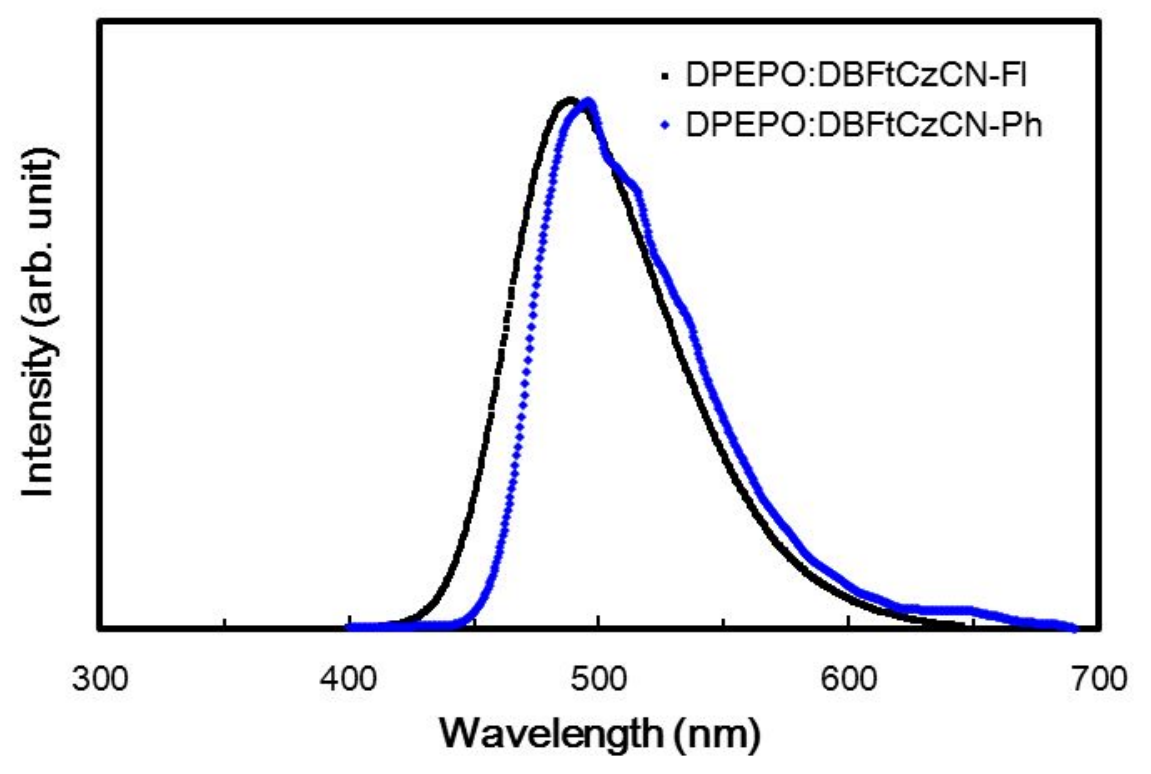

Figure S5. Fluorescence and phosphorescence spectra of $\mathrm{DBFCzCN}$ and $\mathrm{DBFtCzCN}$ doped DPEPO films. 

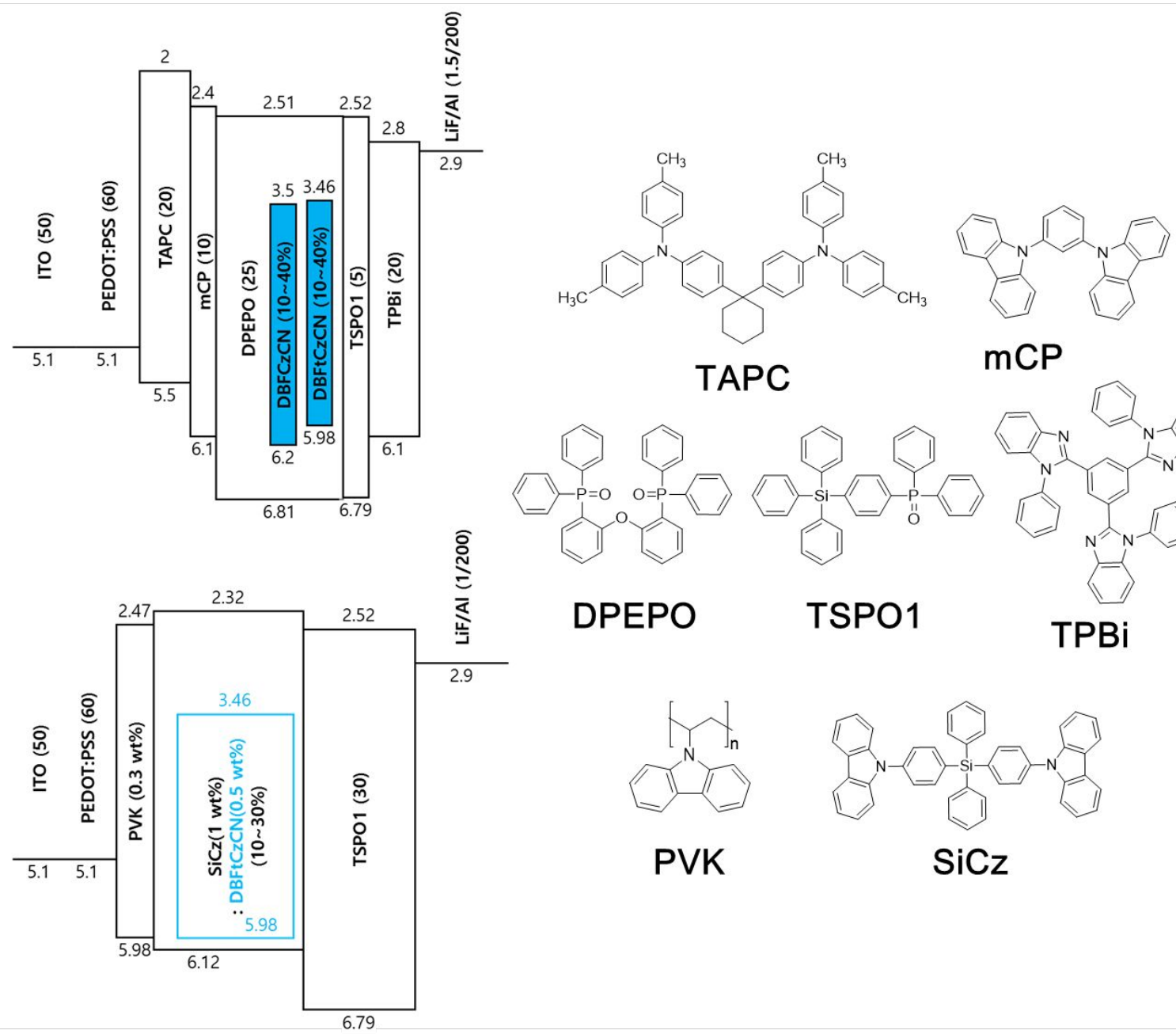

DPEPO
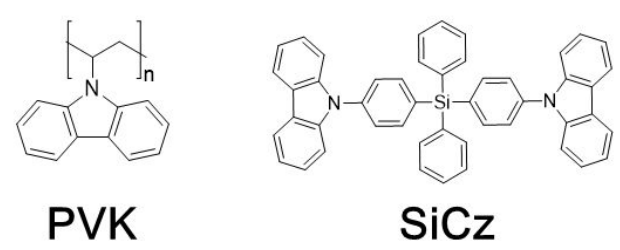

Figure S6. Energy level diagram and chemical structure of the materials. 
(a)

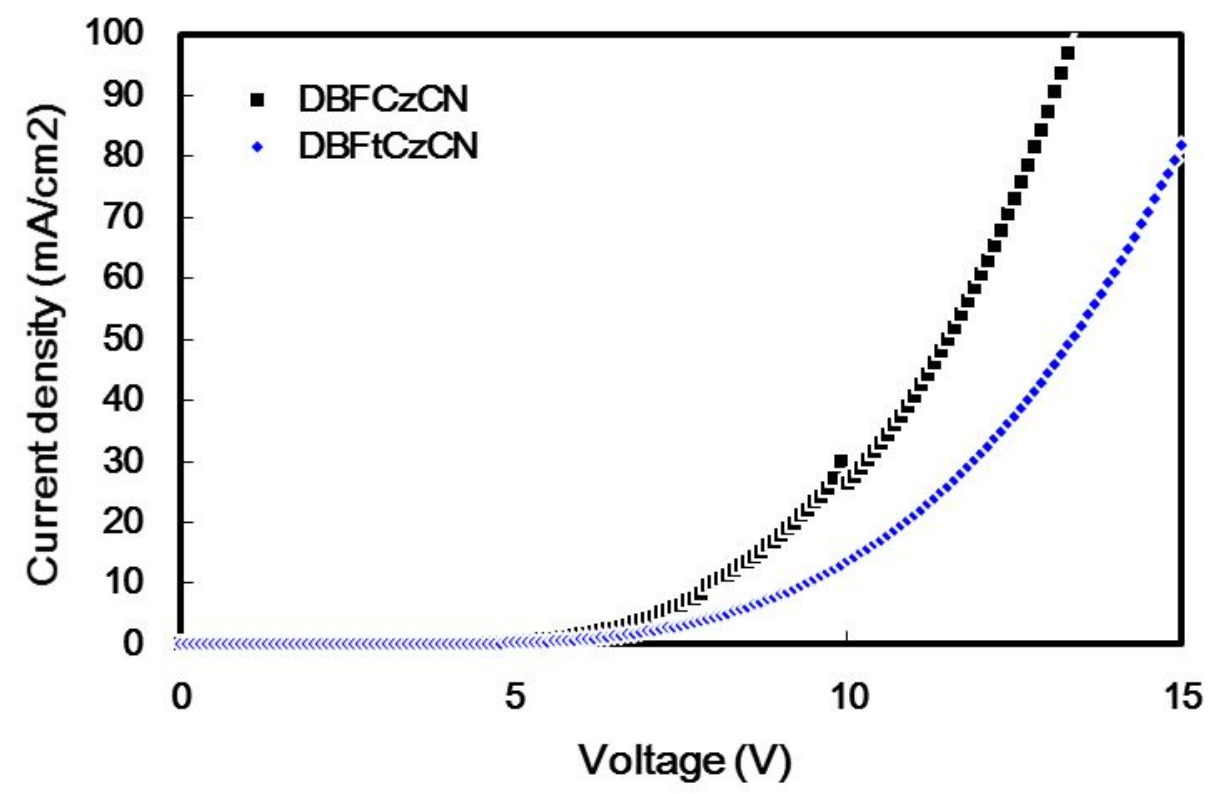

(b)

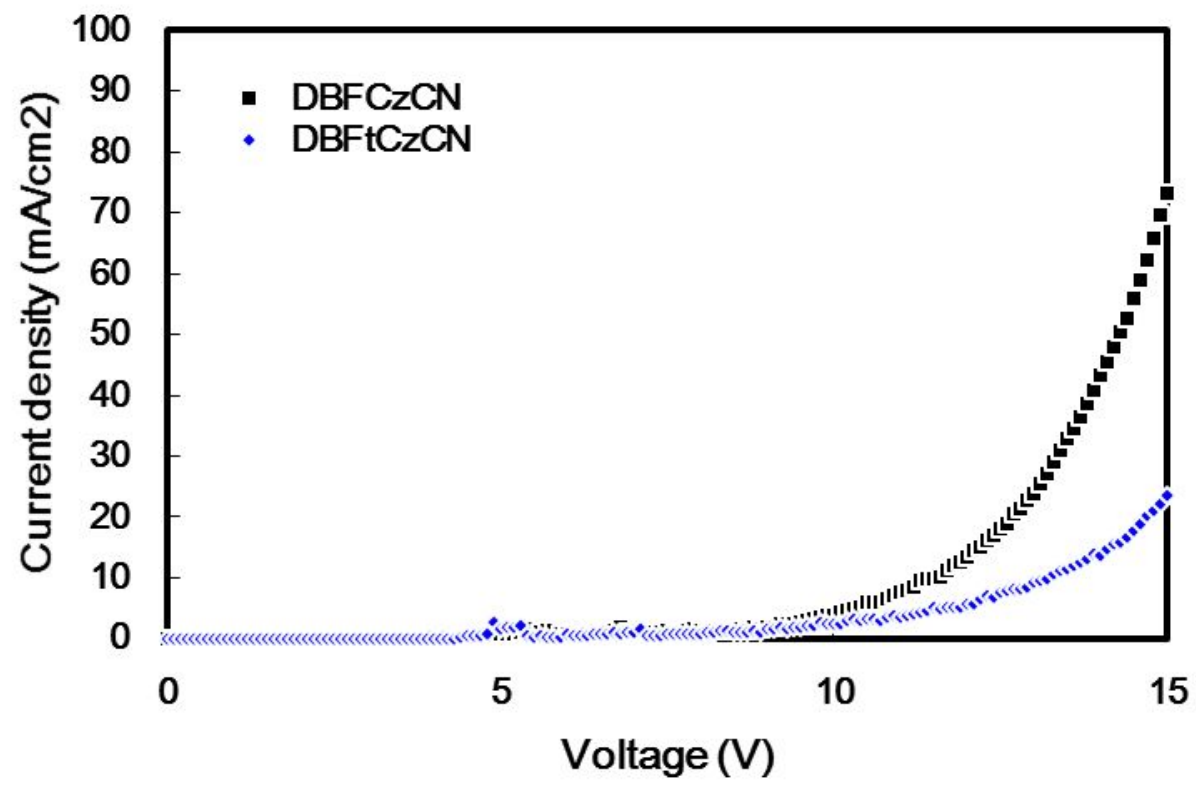

Figure S7. Hole only (a) and electron only (b) device data of DBFCzCN and DBFtCzCN. 
(a)

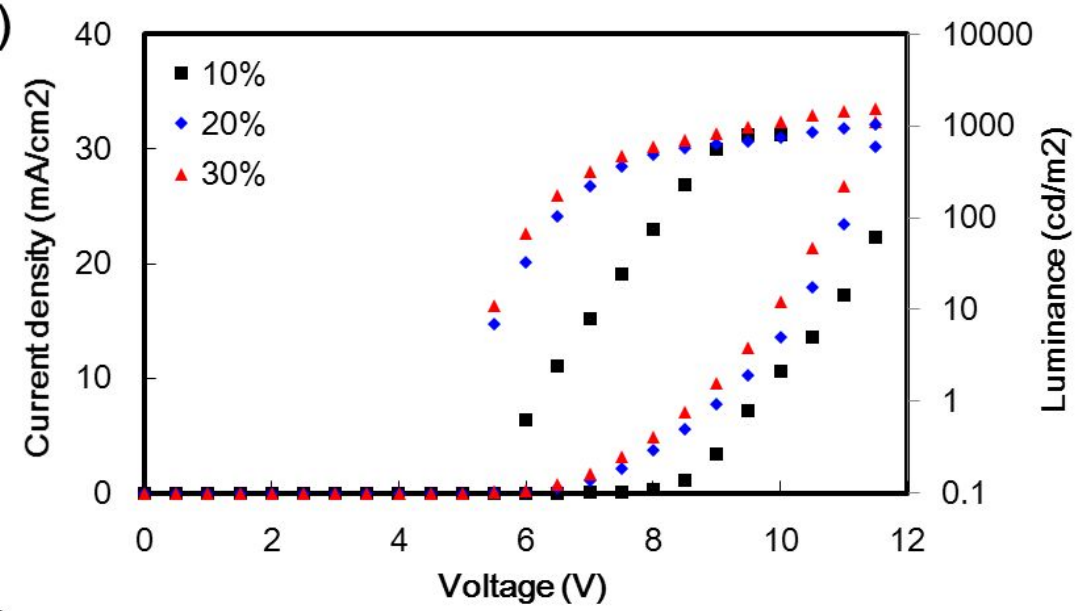

(b)

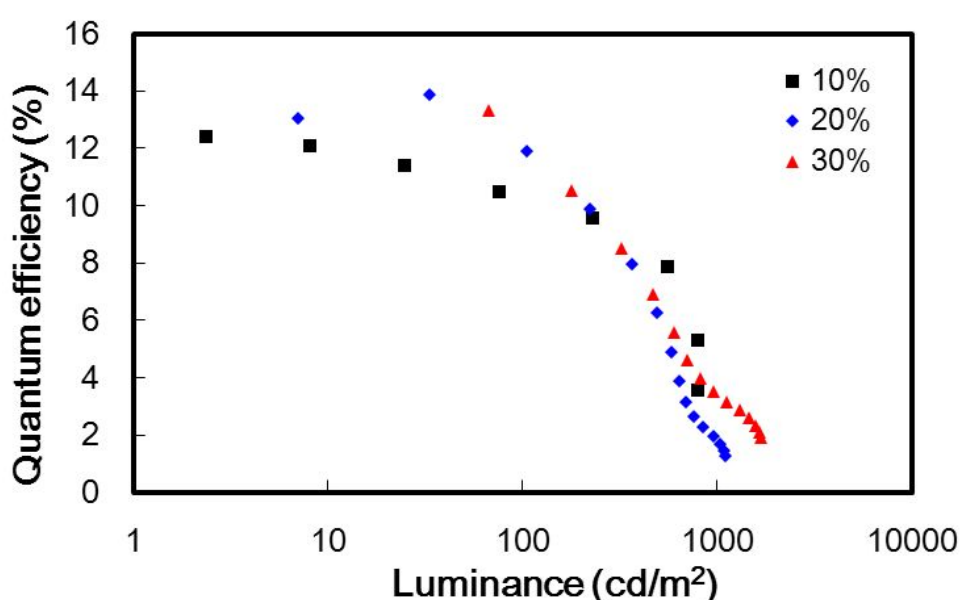

(c)

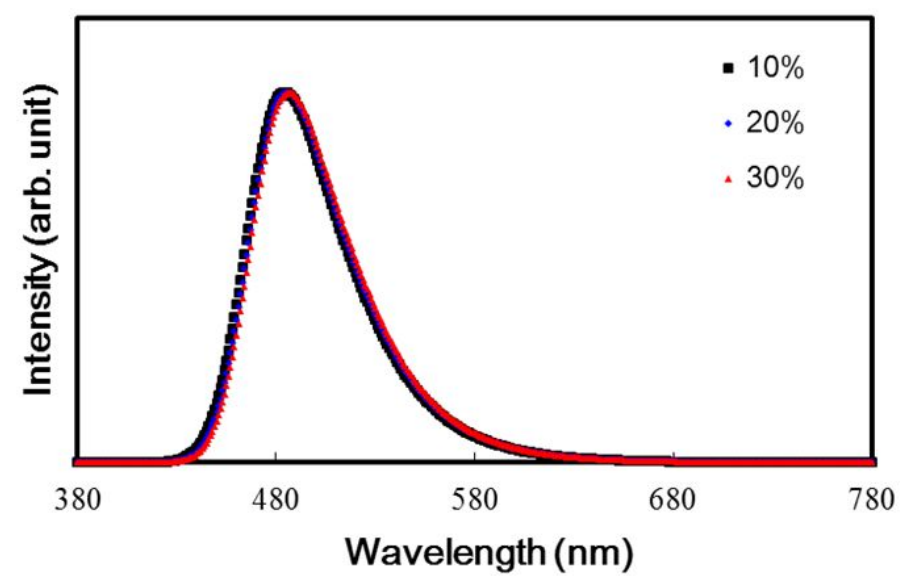

Figure S8. Current density-voltage-luminance (a), EQE-luminance (b) and EL spectra of the solution process DBFtCzCN devices. 